\title{
A Series Hybrid Electric Vehicle Simulation and Analysis of Fuel Consumption Alteration in Different Driving Cycles
}

\author{
${ }^{1}$ Onur Serin and ${ }^{2}$ Dilara Albayrak Serin \\ ${ }^{* 1}$ Department of Automotive Engineering, Kocaeli University, Kocaeli, Turkey \\ ${ }^{2}$ Graduate School of Natural and Applied Sciences, Sabancı University, Istanbul, Turkey
}

\begin{abstract}
With decrease in amount of carbon fuels and aims of creating a cleaner environment, researches on hybrid electric vehicle technology have increased in years. The purpose of this study is to observe the change in fuel consumption of a simulated hybrid electric vehicle in different driving cycles. For this research, a series hybrid electric vehicle is modelled on MATLAB/Simulink. Subsequently, for simulating the tour of the vehicle, multiple driving cycles are modelled on the software and fed to vehicle model. For instance NEDC, WLTC and UDDS, NYCC and J10-15 are benefited, modelled and simulated. Behavior of the vehicle on these routes are observed. After analyzing vehicle behavior in all these cycles, fuel consumption in each case is calculated and compared. As the result of this research, the most affordable cycle for this vehicle model is selected and possible ways of decreasing fuel consumption in other driving cycles is discussed.
\end{abstract}

Key words: Driving cycles, fuel consumption, hybrid electric vehicles, simulation

\section{Introduction}

Hybrid electric vehicles have been in existence since before the $20^{\text {th }}$ century, but researches on this topic have increased in the least 15 years [1]. One of the main reasons behind this concern is that with announcement of the Paris Agreement in 2016, increase in the global temperature in every year is restricted below $2^{\circ} \mathrm{C}$ degrees above pre-industrial temperature values [2]. So research studies over vehicle energization have shifted towards clean options which do not produce emission gasses or global warming by no means. The best answer for clean vehicles are battery electric vehicles and hybrid electric vehicles. Due to contemporary battery chemistry technology and range concerns, development studies are mostly carried over hybrid electric vehicles. Another advantage of hybrid electric vehicles over cars with internal combustion engines is that they have better fuel economy in congested roads since they utilize an electrified drive system with an overall improved system efficiency [3]. In addition, hybrid electric vehicles provide high fuel savings in various commercial usages with start and stop drive cycles. For instance shuttle busses, delivery trucks experience high amount of stop and go drive behavior in everyday use [4]. Before going into details about this new study, hybrid electric vehicle phenomenon should be explained in details. Hybrid electric vehicle is a generic term utilized for addressing vehicles which use a combination of power options. In other words hybrid electric vehicles gather an internal combustion engine and one or more electric motors along with an energy storing body [5].

*Corresponding author: Address: Institute of Natural and Applied Sciences, Kocaeli University, Kocaeli / TURKEY. E-mail address: serinonur@gmail.com 
Having two separate power sources (an internal combustion engine and an electric motor) yields two traction degrees of freedom hence power management in hybrid electric vehicles can be optimized in a better way [4]. Hybrid electric vehicle concept offers supplementary flexibility to minimize fuel consumption and harmful gas production [6]. When these developments around the World and improvement potentials are considered, importance of hybrid electric vehicles and why there should be more studies can be understood [7]. In this particular study the aim is to model a series hybrid electric vehicle on MATLAB/Simulink and analyze vehicle fuel and energy consumption on different drive cycles. During this research several regulative drive cycles are utilized. Benefitted legislative drive cycles are NEDC, UDDS, J10-15, WLTC and NYCC. To be able to understand differences among these cycles and comprehend simulation results, each cycle will be explained in detail. The first cycle is NEDC which is abbreviation of new European drive cycle. This cycle is used for vehicle certification while monitoring pollutive gas productions by the vehicles [8]. As in this study, NEDC can also be utilized for measuring energy need of the vehicle during a cruise [9].

WLTC stands for worldwide harmonized light duty test cycle and it is evaluated for drive ability of the vehicle. This cycle is formed by World Forum (WP.29) of the United Nations Economic Commission for harmonization of vehicle regulations. WLTC cycle has four speed stages which are low speed, medium speed, high speed and extra high speed. This drive cycle is created to show typical driving behavior from all around the World. This cycle is derived from real world driving data which are from Europe, United States of America, India, Korea and Japan [10]. UDDS represents urban dynamometer driving schedule. This cycle simulates the city driving conditions. It is mostly utilized for light duty vehicles [11]. Moreover, UDDS cycle is built in late 1960s inspired from city of Los Angeles [12]. NYCC stands for New York City cycle which mainly simulates low speed traffic with high amount of stop and go traffic conditions [11]. This cycle has very low average speed but high peak acceleration values [13]. Average speed of this cycle is 11.5 $\mathrm{km} / \mathrm{h}$ and the maximum speed is $44.6 \mathrm{~km} / \mathrm{h}$. NYCC is also known as low speed urban drive cycle [14]. J10-15 drive cycle represents Japanese cycle which is used explicitly in Japan for vehicle certification. This cycle represents multiple routes such as urban and motorway with different drive patterns like idling, accelerating and cruising. Distance covered in this cycle is 6.3 kilometers and average speed is $25.6 \mathrm{~km} / \mathrm{h}$ [15].

This paper is constructed by following sections. In material and method section used vehicle model is explained along with necessary vehicle design parameters. Result section is utilized for presenting outcomes of simulations and analysis over different drive cycles. In discussion part acquired results are compared to selected papers from literature.

\section{Materials and Method}

In this study a series hybrid electric vehicle that is a mid-size family car is modelled on MATLAB/Simulink. For calculations, parameters are assigned in accordance with related literature research. Assigned variable values are given in Table 1. 


\begin{tabular}{cc} 
& Table 1. Vehicle Variables \\
Variable & \\
Front area & Value [unit] \\
Number of tyres & $2.33\left[\mathrm{~m}^{2}\right]$ \\
Vehicle weight & 4 \\
Aerodynamic drag coefficient & $1650[\mathrm{~kg}]$ \\
Gravity & 0.3 \\
\hline
\end{tabular}

For vehicle modeling loads acting on the car, which are wheel rolling resistance, air drag resistance, gravitational force due to road slope and mechanical forces, are calculated and implemented to the model. Used formulae for these calculations can be examined below.

Wheel rolling resistance: $F_{r r}=c_{r r} \cdot m \cdot g \cdot \cos \theta$

Air drag resistance: $F_{\text {aero }}=0.5 \cdot c_{d} \cdot \delta \cdot A f \cdot V^{2}$

Gravitational force due to the slope: $F_{\text {slope }}=m \cdot g \cdot \sin \theta$

Mechanical Force: $F_{m e c h}=$ Load due to Mechanical Friction * Number of Wheels

To sum all the forces acting on the vehicle, the total load on the vehicle is represented with $\mathrm{F}_{T}$. $\mathrm{F}_{\mathrm{T}}$ is calculated as:

$$
\mathrm{F}_{\mathrm{T}}=\mathrm{Frr}+\text { Faero }+ \text { Fslope }+ \text { Fmech }
$$

To select the vehicle battery a detailed examination is carried out. While doing this research, keeping battery cost under a limit is also aimed. As the result, Panasonic NCR 18650B [16] battery model is selected. This battery has 345 Volts of nominal voltage. In this study a detailed internal combustion engine is not modelled. Nevertheless a small internal combustion engine which acts as a range extender is modelled. After completing vehicle model, drive cycles are also fed to MATLAB. Vehicle model is run for multiple times in order to observe behavior over different drive cycles. Results of these analysis are presented in following section.

\section{Results}

The first simulation is carried over NEDC drive cycle. Velocity profile of the cycle and velocity profile of the modelled vehicle can be examined in Figure 1. 


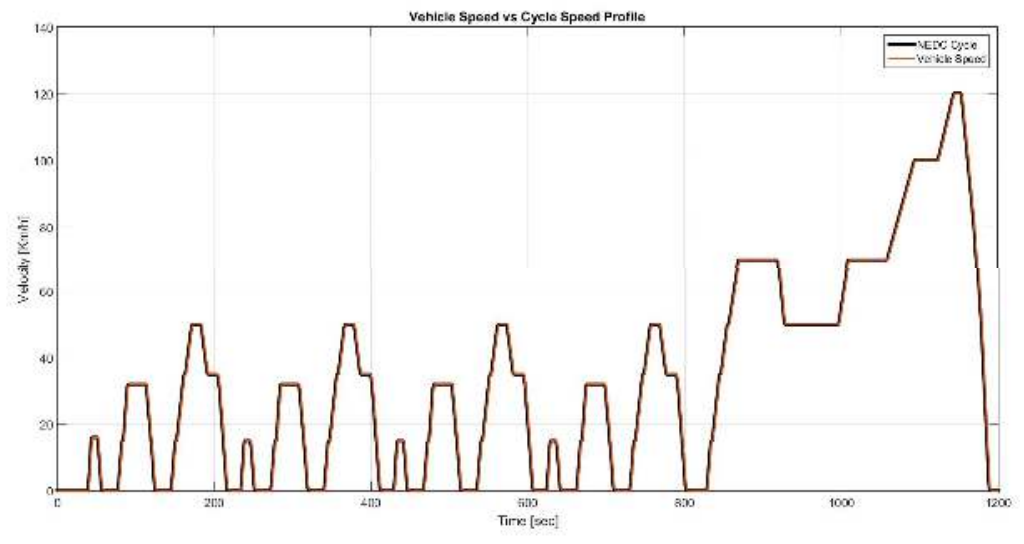

Figure 1. Velocity Profile over NEDC

In this simulation, vehicle cruises over 11 kilometers of distance with $33.1 \mathrm{~km} / \mathrm{h}$ average speed. It is found that in NEDC drive cycle modelled vehicle consumes $1.19 \mathrm{kWh}$ energy. This value corresponds to $10.8 \mathrm{kWh} / 100 \mathrm{~km}$ value. When cost of gasoline is assumed as 5.5 Turkish Liras per liter and cost of electricity is assumed as 0.2 Turkish Liras per kWh, total trip cost per 100 kilometers is calculated as 2.2 Turkish Liras. Following simulation is done for UDDS drive cycle which is formed by 12 kilometers distance with average speed of $31.5 \mathrm{~km} / \mathrm{h}$. Velocity profiles can be seen in Figure 2.

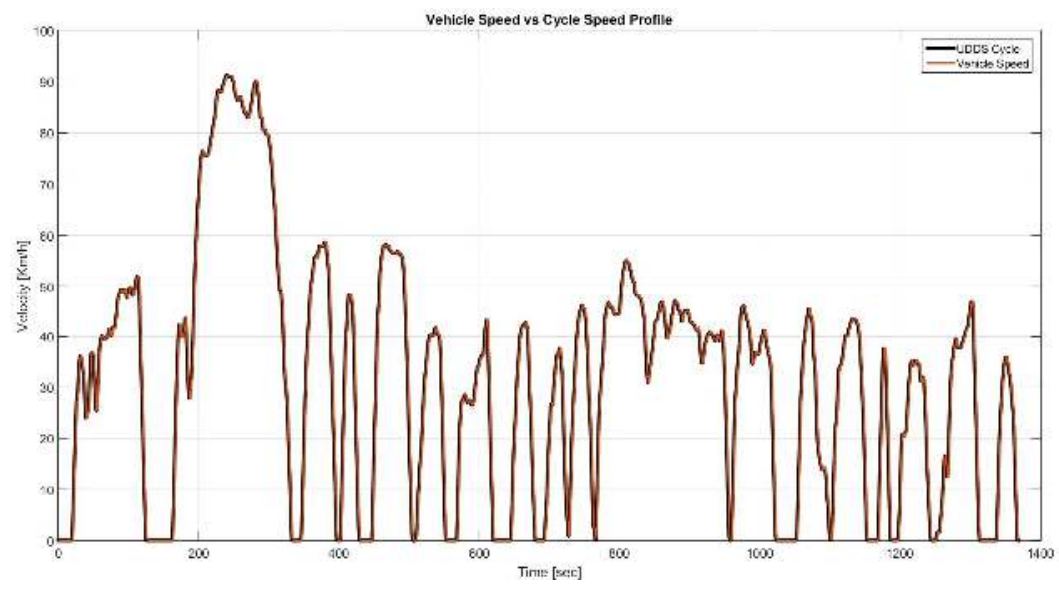

Figure 2. Velocity Profile over UDDS

Total consumption in this analysis is found as $1.09 \mathrm{kWh}$. When trip cost is calculated with previously assumed gasoline and electricity prices, cost for this drive cycle is calculated as 1.8 Turkish Liras per 100 kilometers. 
Another analysis is held for WLTC drive cycle. This cycle is built from a distance of 23.3 kilometers with $46.5 \mathrm{~km} / \mathrm{h}$ average speed. When trip cost is calculated it is found as 3.0 Turkish Liras per 100 kilometers. Total electric power consumption in this case is $3.46 \mathrm{kWh}$. Velocity profile of this case is presented in Figure 3, below.

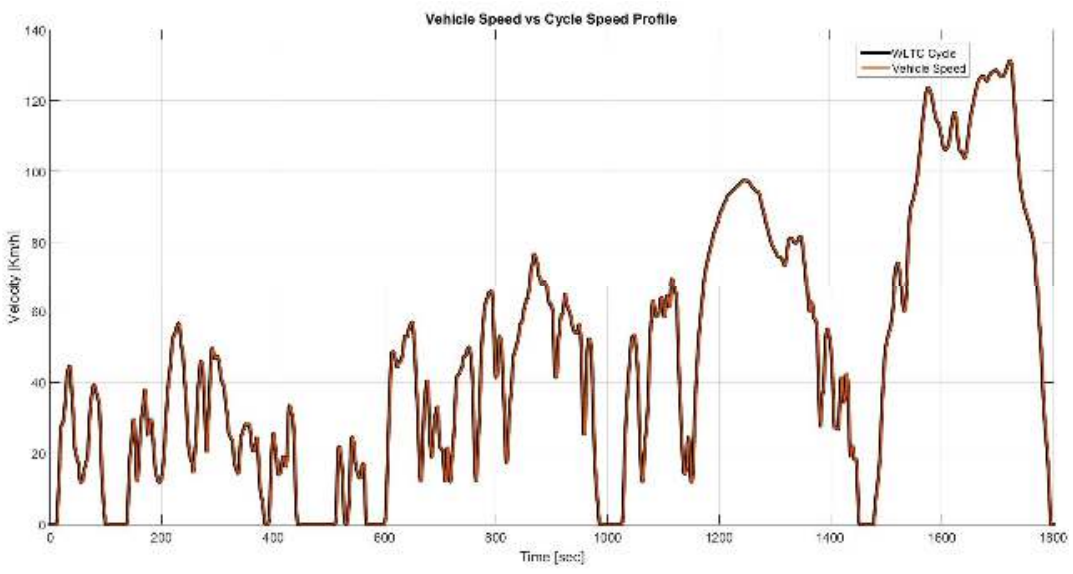

Figure 3. Velocity Profile over WLTC

Following simulation is carried over NYCC drive cycle which mainly represents a start and go traffic jam hence average velocity in this cycle is only $11.5 \mathrm{~km} / \mathrm{h}$. Distance travelled in this case is 1.9 kilometers. Total electricity consumption in this cycle is $0.23 \mathrm{kWh}$. Through cost assumptions, trip cost per 100 kilometers is found as 2.4 Turkish Liras. Velocity profile of this case is presented in Figure 4, below.

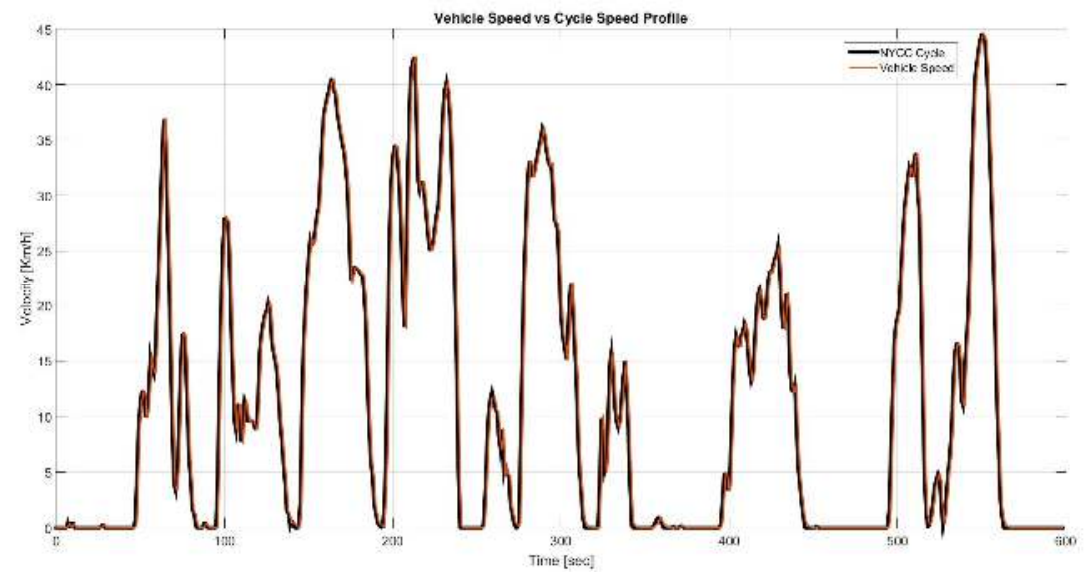

Figure 4. Velocity Profile over NYCC

The last case study is done with utilization of Japanese drive cycle, J10-15. This cycle is 6.3 kilometers and average speed is $25.6 \mathrm{~km} / \mathrm{h}$. Total consumption in this cycle is $0.48 \mathrm{kWh}$. When calculated, cost per $100 \mathrm{~km}$ is found as 1.5 Turkish Liras. Velocity profile of this case is presented in Figure 5. Comparison of all utilized legislative cycles can be examined in Table 2. In addition, cost per 100 kilometers values can be observed in Figure 6. 


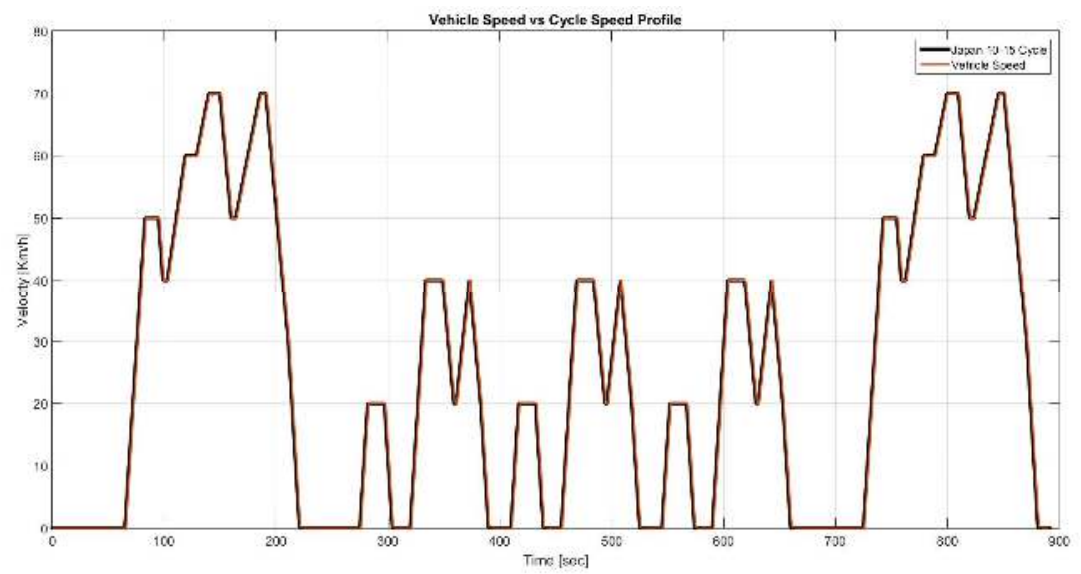

Figure 5. Velocity Profile over J10-15

Table 2. Regulative Drive Cycle Comparisons

$\begin{array}{lcccccc}\text { Cycles } & \begin{array}{c}\text { Distance } \\ {[\mathbf{k m}]}\end{array} & \begin{array}{c}\text { Total } \\ \text { Consumption } \\ {[\mathbf{k W h}]}\end{array} & \begin{array}{c}\text { Average } \\ \text { Speed } \\ {[\mathbf{k m} / \mathbf{h}]}\end{array} & \begin{array}{c}\text { Consumption } \\ \mathbf{k W h} / \mathbf{1 0 0 k m}\end{array} & \begin{array}{c}\text { Cost per } \\ \mathbf{1 0 0 K m} \\ {[\mathbf{T L}]}\end{array} & \begin{array}{c}\text { Consumption } \\ \mathbf{W h} / \mathbf{k m}\end{array} \\ \text { NEDC } & 11.0 & 1.19 & 33.1 & 10.8 & 2.2 & 108 \\ \text { UDDS } & 12.0 & 1.09 & 31.5 & 9.1 & 1.8 & 91 \\ \text { WLTC } & 23.3 & 3.46 & 46.5 & 14.9 & 3.0 & 149 \\ \text { NYCC } & 1.9 & 0.23 & 11.5 & 12.2 & 2.4 & 122 \\ \text { J10-15 } & 6.3 & 0.48 & 25.6 & 7.5 & 1.5 & 75\end{array}$

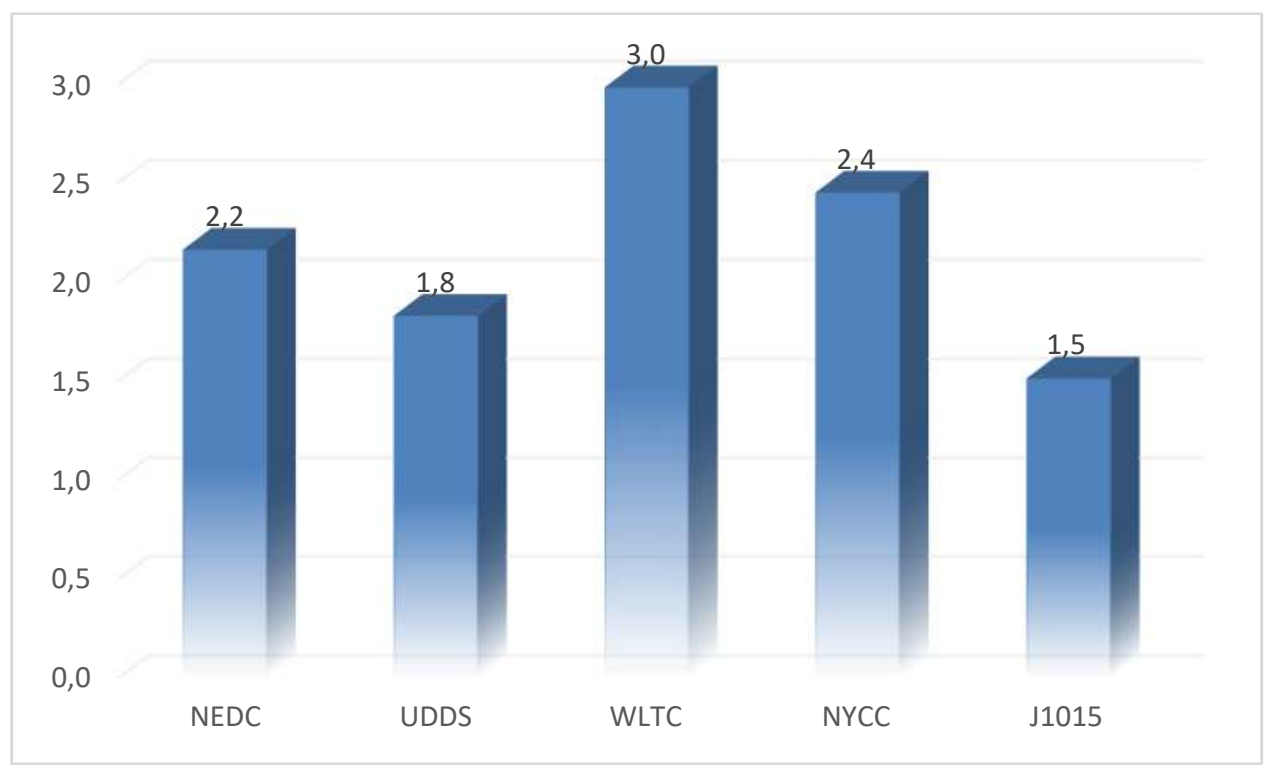

Figure 6. Cost Comparison per $100 \mathrm{~km}$ 
And at last, a comparison for cycles over one trip in terms of consumed energy versus distance is built as a graph and given in Figure 7.

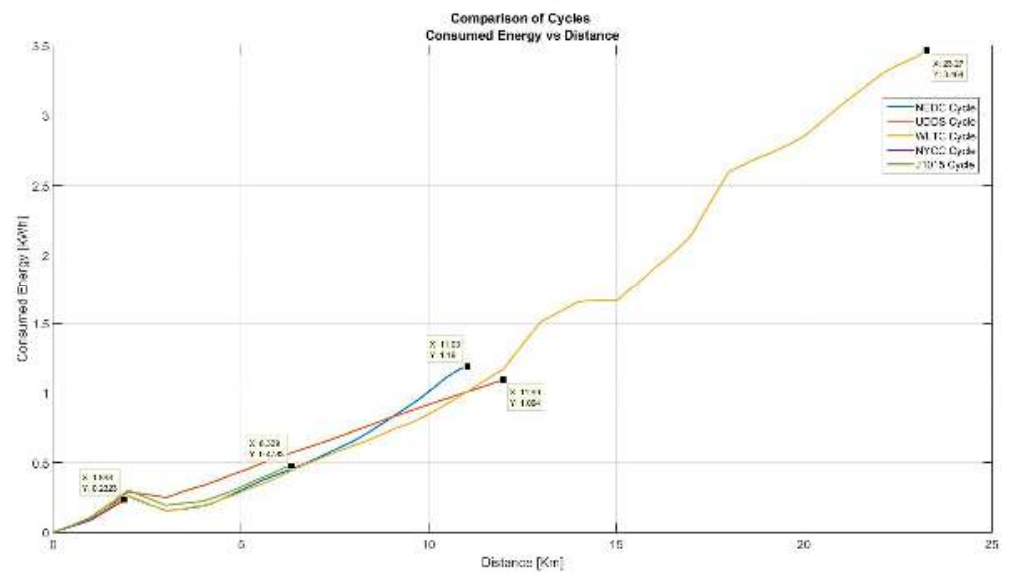

Figure 7. Consumed Energy versus Distance Graph for one Trip in All Cycles

\section{Discussion}

In this part comparison of analysis results to sample papers from literature is carried out. The first paper from literature is done by Boscaino and Miceli [17] in 2015. In this study researchers aim to analyse drive cycle effect over power need of a light weight hybrid electric vehicle. For analysis purposes a legislative drive cycle, European urban drive cycle (EUDC) and a privately formed routed, congested roads of Naples are benefitted. As the result, it is proposed that hybrid electric vehicle designs can be done much more efficiently when real life drive cycle patterns are utilized. It is also mentioned that regulative road patterns lack showing the critical driving conditions thus only considering these drive cycles are not adequate for improved designs.

Second story from literature is written by Tang and Rizzoni [18] in 2016. Researchers model a pretransmission hybrid electric vehicle and aim to optimize energy management concept of the vehicle. Again in this paper legislative cycles federal urban drive cycle (FUDC) and US06 are used. Simulations for both drive cycles are done. Additionally these analysis provide an insight over driving behaviour which are aggressive and urban drive types. As the results, it is supported that due to aggressive driving pattern in US06 cycle, fuel saving in this particular cycle is rather small when compared to FUDC.

Another example from literature is carried out by Karabasoglu and Michalek [19] in 2013 on observing influence of driving cycles over life cycle cost and emissions of hybrid electric vehicles. In this study researchers work with multiple drive cycles which are NYCC, highway test conditions (HWFET) and US06 for showing aggressive driving profile. As the result of this study, it is reached that usage of regulative cycles for vehicle performance assessments is crucial. Moreover, writers suggest that usage of hybrid electric vehicles on HWFET and NYCC drive cycles offer dramatic cost reductions. 
This new study is done via modelling a series hybrid electric vehicle on MATLAB/Simulink and analysing its fuel consumption and trip cost values over multiple drive cycles such as NEDC, UDDS and WLTC. From simulations it is interpreted that the highest average velocity is achieved in WLTC cycle but this cycle also has the highest trip cost over $100 \mathrm{~km}$. Following cycle for consumption category is NYCC due to modelled traffic jam. According to outcomes it can be commented that Japanese drive cycle, J10-15 has the cheapest cruise when compared to others.

\section{Conclusions}

To conclude, this paper can be summarized as a modeling and simulation process of a hybrid electric vehicle for observing its behaviour while cruising over different drive cycles. Prior to simulations, a mid-size family sedan type of a car is selected and modelled on MATLAB/Simulink. After modelling of the whole vehicle, multiple legislative drive cycles, which are NEDC, UDDS and so on, are modelled. In simulation stage, the vehicle is run on each cycle and fuel consumption, electric power consumption and total trip cost for each case is calculated. Acquired numeric data are compared to each other for finding the most consuming drive cycle. From the results it is seen that for this particular vehicle WLTC drive cycle has the highest amount of consumption over 100 $\mathrm{km}$. In the future studies, elaborating this idea over privately modelled roads from Turkey is aimed. For instance simulating modelled vehicle over a route from Turkey and comparing regulative drive cycle results to this new concept is an idea researchers are currently working on.

\section{References}

[1] A. Sciarretta and L. Guzeella, "Control of Hybrid Electric Vehicles," IEEE Control Systems Magazine, vol. 27, no. 2, pp. 60-70, 042007.

[2] OECD/IEA, “Global EV Outlook 2017,” OECD, 2017.

[3] Y. Zhao, M. L. Kuang, A. M. Phillips and J. Kristionsson, "Path-forecasting for HEV Optimal Energy Management (POEM)," in American Control Conference (ACC), Boston, MA, USA, 2016.

[4] C. Patil, P. Naghshtabrizi, R. Verma, Z. Tang, K. Smith and Y. Shi, "Optimal BAttery Utilization OVer LIfetime For Parallel Hybrid Electric Vehicle to Maximize Fuel Economy," in 2016 American Control Conference (ACC), Boston, MA, USA, 2016.

[5] C. Guardiola, B. Pla and G. Rizzoni, "Insight into the HEV/PHEV Optimal Control Solution Based on a New Tuning Method," Control Engineering Practice, vol. 29, pp. 247-256, 2014.

[6] V. H. Johnson, K. B. Wipke and D. Rausen, "HEV Control Strategy for Real-Time Optimization of Fuel Economy and Emissions," National Renewable Energy Laboratory, 2000 . 
[7] D. Albayrak Serin and M. A. Özpınar, "Modeling and Simulation of Driving Performance in a Series Hybrid Electric Vehicle," in 9th International Automotive Technologies Congress, OTEKON 2018, Bursa, Turkey, 2018.

[8] B. Degraeuwe and M. Weiss, "Does the New European Driving Cycle (NEDC) really fail to capture the NOX emissions of diesel cars in Europe?," Environmental Pollution, vol. 222, pp. 234-241, March 2017.

[9] G. Zhu, J. Liu, J. Fu, Z. Xu, Q. Guo and H. Zhao, "Experimental study on combustion and emission characteristics of turbocharged gasoline direct injection (GDI) engine under cold start new European driving cycle (NEDC)," Fuel, vol. 215, no. 1, pp. 272-284, March 2018.

[10] M. Tutuianu, A. Marotta, H. Steven, E. Ericsson, T. Haniu, N. Ichikawa and H. Ishii, "Development of a World-wide Worldwide harmonized Light duty driving Test Cycle (WLTC)," Development of the Harmonized driving Cycle (DHC) Sub-group, 2014.

[11] U. S. E. P. A. (EPA), "Vehicle and Fuel Emissions Testing Dynamometer Drive Schedules," $31 \quad 012017 . \quad$ [Online]. Available: https://www.epa.gov/vehicle-and-fuel-emissionstesting/dynamometer-drive-schedules. [Accessed 1508 2018].

[12] E. Nam, "Drive Cycle Development and Real-world data in the United States," United NAtions Economic Commission, Geneva, Switzerland, 2009.

[13] J. W. Whitefoot, K. Ahn and P. Y. Paplambros, "The Case for Urban Vehicles: Powertrain Optimization of a Power-split Hybrid for Fuel Economy on Multiple Drive Cycles," in ASME 2010 International Design Engineering Technical Conferences \& Computers and Information in Engineering Conference, Montreal, Quebec, Canada, 2010.

[14] "EPA New York City Cycle (NYCC)," [Online]. Available: https://www.dieselnet.com/standards/cycles/nycc.php. [Accessed 1508 2018].

[15] R. Nicolas, "The different driving cycles," 0105 2013. [Online]. Available: http://www.carengineer.com/the-different-driving-cycles/. [Accessed 1908 2018].

[16] S. E. Corporation, Panasonic Lithium Ion NCR18650B, 2012.

[17] V. Boscaino and R. Miceli, "Analysis of driving cycles effects on power supply requirements of a fuel cell powered light-weight electric vehicle," in 2015 IEEE International Electric Machines \& Drives Conference (IEMDC), Coeur d'Alene, ID, USA, 2015. 
[18] L. Tang and G. Rizzoni, "Energy Management Strategy Including Battery Life Optimization for a HEV with CVT," in 2016 IEEE Transportation Electrification Conference and Expo, Asia-Pacific, Busan, Korea, 2016.

[19] O. Karabasoglu and J. Michalek, "Influence of Driving Patterns on Life Cycle Cost and Emissions of Hybrid and Plug-In Electric Vehicle Powertrains," Energy Policy, vol. 60, pp. 445-461, 2013. 